\title{
Dong Quai (angelica sinensis) in the treatment of hot flashes for men on androgen deprivation therapy: results of a randomized double-blind placebo controlled trial
}

\author{
Reem J. Al-Bareeq, MD, MRCSI, CABU; A. Andrew Ray, MS, MD, FRCSC; Linda Nott, RN; \\ Stephen E. Pautler, BSC, MD, FRCSC; Hassan Razvi, MD, FRCSC
}

See related article on page 54

\section{Abstract}

Objective: To determine whether Dong Quai, a Chinese herbal compound purported to be efficacious in treating menopausal vasomotor symptoms, has a therapeutic benefit in treating hot flashes among prostate cancer patients receiving androgen deprivation therapy.

Methods: A randomized double-blind placebo controlled trial was conducted involving 22 men receiving luteinizing hormone-releasing hormone agonist therapy for prostate cancer with bothersome hot flashes. After recording a baseline log of the frequency, duration and severity of daily hot flashes, patients were randomly assigned in a 1:1 ratio to receive daily placebo or Dong Quai for 3 months. Vasomotor and adverse events were recorded daily. Blood work including serum prostate-specific antigen (PSA), international normalized ratio of prothrombin time and partial thromoboplastin time were recorded at baseline and at the termination of the study.

Results: Seventeen of the 22 patients enrolled completed the trial. Baseline vasomotor duration and severity were equivalent between the groups, however the number of hot flashes were significantly more in the Dong Quai group $(p=0.02)$. With respect to the change in number of hot flashes per day, there was a slight decrease in the mean number among the Dong Quai group which was insignificant. The absolute change and average percentage change in perceived hot flash severity was similar in both groups. There was no significant decrease in the duration of the hot flashes between the 2 groups. Disease progression based on either PSA increase or change in digital rectal exam was not observed in any patient. Conclusion: In this small pilot study, there were no significant differences in the severity, frequency or duration of hot flashes among men receiving placebo or Dong Quai.

Can Urol Assoc J 2010;4(1):49-53

\section{Résumé}

Introduction : Nous avons cherché à déterminer si le Dong Quai (Angelica sylvestris chinensis ou angélique chinoise), une plante médicinale chinoise censée être efficace dans le traitement des symptômes vasomoteurs liés à la ménopause, procure des bien- faits thérapeutiques aux patients atteints de cancer de la prostate présentant des bouffées vasomotrices pendant un traitement antiandrogène.

Méthodologie : On a mené un essai randomisé à double insu et contrôlé par placebo auprès de 22 hommes recevant un agoniste de l'hormone de libération de I'hormone lutéinisante (LHRH) pour le traitement d'un cancer de la prostate et présentant des bouffées vasomotrices incommodantes. Après avoir noté au départ la fréquence, la durée et la gravité des épisodes quotidiens de bouffées vasomotrices, on a réparti les patients aléatoirement selon un rapport de 1:1 pour recevoir chaque jour un placebo ou du Dong Quai pendant 3 mois. Les effets vasomoteurs et les réactions indésirables ont été notés chaque jour. Des analyses sanguines comprenant le taux sérique d'APS et le rapport international normalisé du temps de Quick et du temps de thromboplastine partielle ont été effectuées au départ et à la fin de l'étude.

Résultats : Dix-sept des 22 patients inscrits ont participé à l'étude jusqu'à la fin. La durée et la gravité des épisodes de bouffées vasomotrices étaient similaires dans les deux groupes au départ, mais le nombre d'épisodes de bouffées vasomotrices était significativement plus élevé dans le groupe recevant le Dong Quai $(p=0,02)$. En ce qui a trait à la variation dans le nombre d'épisodes quotidiens, une légère diminution a été notée dans le nombre moyen dans le groupe sous Dong Quai mais cette diminution s'est avérée non significative. La variation absolue et le pourcentage moyen de variation dans la gravité perçue des épisodes de bouffées vasomotrices étaient similaires dans les deux groupes. On n'a noté aucune diminution de la durée des épisodes dans les deux groupes. Aucune progression de la maladie, en fonction de changements dans les taux d'APS ou lors des touchers rectaux n'a été notée.

Conclusion : Dans cette petite étude pilote, aucune différence significative n'a été observée dans la gravité, la fréquence ou la durée des bouffées vasomotrices chez les hommes recevant un placebo ou du Dong Quai.

\section{Introduction}

Dong Quai, derived from the root of the Chinese herb Angelica sinensis, has been used for thousands of years in traditional Far Eastern medicine. Dong Quai has been named "female ginseng" because of its use for various health 
conditions afflicting women including dysmenorrhea, pelvic pain, recovery from childbirth and menopausal symptoms, such as hot flashes. ${ }^{1}$

Three randomized controlled trials have examined the use of Dong Quai for perimenopausal symptoms and menstrual migraine. ${ }^{2-4}$ Overall vasomotor episode reduction was noted in $20 \%$ to $35 \%$ of patients in several studies ${ }^{2,4}$ although another study failed to show any significant difference between Dong Quai and placebo. ${ }^{3}$ The study by Burke and colleagues did demonstrate a $56 \%$ reduction in menstrually associated migraine attacks. ${ }^{3}$

It is believed the physiologic mechanisms involved in the development of menopausal hot flashes in women and men prescribed androgen deprivation therapy (ADT) are analogous. Although the exact etiology of hot flashes is unknown, several theories have been proposed including increases in hypothalamic adrenergic levels, alterations in ß-endorphins and a potential role of calcitonin gene-related peptides within the thermoregulatory centre in the hypothalamus. ${ }^{5,6}$

It is well-established that the use of gonadotropin-releasing hormone agonist $(\mathrm{GnRH})$ analogues are associated with hot flashes in more than $75 \%$ of patients. ${ }^{7,8}$ One study suggested that the frequency and severity of vasomotor symptoms were most prominent during the first year after castration. ${ }^{9}$ In contrary to postmenopausal hot flashes that usually disappear after 2 to 5 years, for men after orchidectomy or receiving continuous $\mathrm{GnRH}$ therapy, vasomotor symptoms usually persist. The duration of the symptoms may therefore be quite long, given that many more men are receiving these agents at an earlier stage in their disease.

The use of Dong Quai to manage hot flashes in men receiving ADT has not been previously reported to our knowledge and is the basis of this research.

\section{Methods}

We conducted a prospective randomized, double-blinded, placebo, controlled trial to assess the potential efficacy of Dong Quai in improving symptomatic hot flashes in men receiving ADT. The study was approved by The University of Western Ontario Health Sciences Research Ethics Board. Twenty-two patients receiving luteinizing hormone-releasing

Table 1. Patient demographics

\begin{tabular}{lccc}
\hline & Placebo & Dong Quai & $\boldsymbol{p}$ \\
\hline & $\mathrm{n}=11$ & $\mathrm{n}=11$ & $\mathrm{n} / \mathrm{a}$ \\
\hline Age & $74.0 \pm 8.15$ & $72.5 \pm 9.63$ & 0.69 \\
PSA & $0.21 \pm 0.38$ & $0.30 \pm 0.33$ & 0.57 \\
INR & $1.02 \pm .01$ & $1.06 \pm 0.01$ & 0.19 \\
PTT & $30.6 \pm 2.8$ & $32.1 \pm 2.5$ & 0.29 \\
\hline
\end{tabular}

PSA = prostate-specific antigen; INR = international normalized ratio of prothrombin time; $\mathrm{PTT}=$ partial thromoboplastin time. Values represent mean \pm standard deviations. hormone (LHRH) agonist monotherapy with either goserelin acetate, buserelin acetate or leuprolide were enrolled between January 2002 and July 2007. Indications for ADT in these patients included radiographically confirmed metastatic disease or biochemical progression following prior attempt(s) at definitive therapy. Men in this trial had been on ADT for an average of 17 months (range 2 to 51) before enrollment. The patients were randomized 1:1 to receive either Dong Quai or placebo. The herbal preparation (Swiss Herbal Remedies Ltd, Richmond Hill, Ontario) contained $500 \mathrm{mg}$ of Dong Quai. The placebo preparation was an inert tablet manufactured by our hospital pharmacy to visibly resemble the Dong Quai tablet.

Exclusion criteria included: involvement in another clinical trial, pain requiring daily use of analgesics, life expectancy of less than 3 months, receiving anticoagulant therapy, history of bleeding disorder or known hypersensitivity to any constituent of DQ.

At each follow-up visit, participants completed a followup questionnaire where they noted any change in their prescribed or over-the-counter medications, change in their physical health and whether or not they had taken the study drug as instructed. Compliance was also assessed by counting the pills remaining in the returned study drug bottle.

The primary outcome measure assessed was the reduction in the incidence and severity of vasomotor episodes using an event log and symptom questionnaire at each of the 3 follow-up visits. The event log was used to document the severity of hot flashes, using a visual analog scale (VAS), and also to determine the date and time of hot flash events. The incidence of events was calculated by the number of events over time. The severity of an individual event was determined by using the average number of events recorded and the average VAS. The percent change in vasomotor occurrences and severity from baseline to each month of the study was calculated and compared between groups.

Both groups were subjected to an initial questionnaire to document the baseline hot flash symptom frequency and bother. Laboratory testing included determinations of prostatespecific antigen (PSA), partial thromoboplastin time (PTT) and international normalized ratio of prothrombin time (INR). At 1 month, a run-in period of assessment was then conducted to record the frequency, severity and duration of all vasomotor events. The event severity was subjectively quantified by

Table 2. Hot flashes at baseline

\begin{tabular}{lccc}
\hline & Placebo & Dong Quai & $\boldsymbol{p}$ \\
\hline $\mathrm{n}=11$ & $\mathrm{n}=11$ & $\mathrm{n} / \mathrm{a}$ \\
\hline Episodes per day & $3.42 \pm 1.42$ & $6.80 \pm 4.33$ & 0.02 \\
Severity (0 - 10) & $3.64 \pm 1.37$ & $3.76 \pm 1.67$ & 0.79 \\
Duration in minutes & $4.83 \pm 3.38$ & $3.33 \pm 1.45$ & 0.19 \\
\hline
\end{tabular}

$\mathrm{n} / \mathrm{a}=$ not applicable. Values represent mean \pm standard deviations 


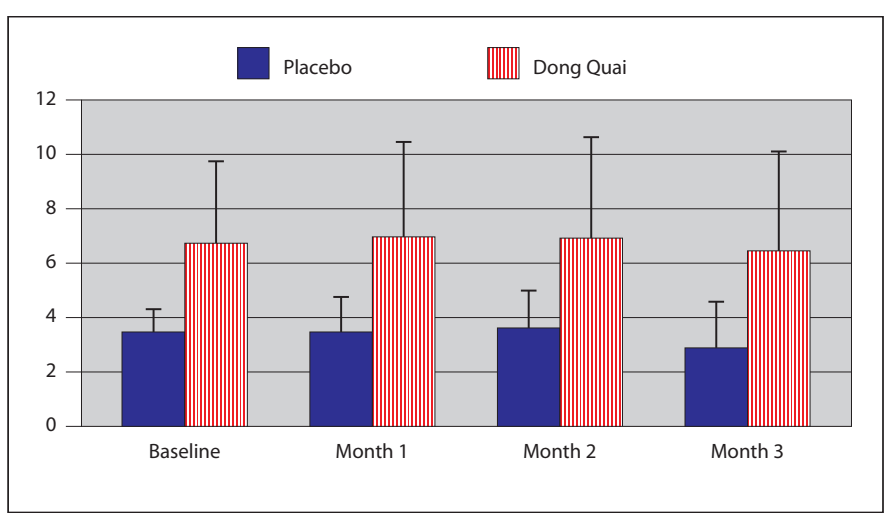

Fig. 1. Vasomotor events per day. Overall the Dong Quai group experienced more hot flashes than the Placebo group $(p=0.02)$. There was no change in the number of daily vasomotor events in either group ( $p=$ not significant).

the patients using a 10-cm VAS. Patients kept daily records of these events which would be reviewed and collected each month by the research nurse. The study was done over a span of 4 months including the 1-month run-in, with all patients taking a daily pill each morning for 3 months. At the end of the study, repeat PSA, INR and PTT were tested.

The data were analyzed using Students' t-test and twoway analysis of variance, where appropriate, to compare the effects of treatment between the placebo and active treatment arms. Categorical data was analyzed with the Pearson chi-square test. Test significance was set at $<0.05$.

\section{Results}

Eleven patients were included in the Dong Quai group and 11 in the placebo arm. The patient demographics were similar for both groups (Table 1). The patients' ages ranged from 72.5 to 74.0. The mean values at study entry for PSA, INR and PTT were 0.25, 1.04 and 31.4, respectively. Five patients, 3 from the placebo group and 2 patients from the Dong Quai group, withdrew from the study for reasons including gastrointestinal upset, headache, no perceived benefits, unrelated head injury and scheduling conflicts. No patient reported taking the active study drug from an over-the-counter preparation.

To understand the magnitude of the patients' symptoms, all patients completed questionnaires which revealed that $47.6 \%$ had trouble sleeping due to hot flashes. Only $4.8 \%$ had tried alternative treatments to resolve their hot flashes prior to their participation in this trial.

In the initial 1-month run-in, the placebo group had an average of $3.42 \pm 1.42$ vasomotor episodes per day while the Dong Quai group had $6.80 \pm 4.33$ episodes $(p=0.02)$. The severity of the episodes averaged $3.64 \pm 1.37$ in the placebo group versus $3.76 \pm 1.67$ in the Dong Quai group. The duration of the vasomotor symptoms lasted on average $4.83 \pm 3.38$ minutes in the placebo group and $3.33 \pm$

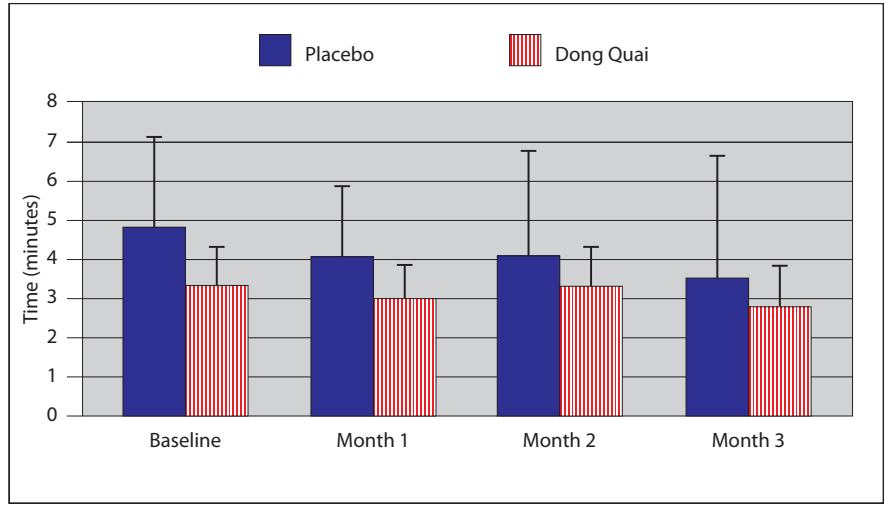

Fig. 2. Duration of vasomotor event. Hot flashes were of similar duration in both the placebo and Dong Quai groups $(p=0.19)$. There was no change in the duration of vasomotor events in either group ( $p=$ not significant).

\subsection{5 minutes in the Dong Quai group (Table 2).}

The average number of vasomotor events experienced by the placebo group was 3.55 in the first month, 3.58 in the second and 2.84 in the third. The average number of vasomotor episodes for the Dong Quai group was 6.9 in the first month, 6.86 in second month and 6.43 in third month. Comparatively, there was no significant change in the daily number of vasomotor events in either group (Fig. 1).

The mean duration of hot flashes in the placebo group in the first month was 4.07 minutes, 4.1 minutes in the second and 3.52 in the third. Patients in the Dong Quai group experienced hot flashes for a mean time of 2.99 minutes in the first month, 3.28 in the second and 2.82 in the third. Neither group experienced a significant change in the average duration of their vasomotor events (Fig. 2).

The average hot flash severity subjectively recorded by patients in the placebo group in the first month was 3.66, in the second month was 3.66 and in the third month was 2.47. The patients in the Dong Quai group experienced 3.87 in severity of hot flashes in the first month, 3.27 in the second month and 3.71 in the third month. Vasomotor events were of similar severity in both groups $(p=0.79)$ (Fig. 3). The calculated percent change in perceived hot flash severity was similar in both groups ranging from 78 to $112 \%$ for the placebo group and 93 to $116 \%$ for the Dong Quai group (Fig. 3).

Coagulation studies were obtained for each patient in both groups before starting the study and at completion. Baseline

Table 3. Dong Quai ingredients

\begin{tabular}{ll} 
Volatile oils & $\begin{array}{l}\text { ligustilide, n-butylidene phtalide, } \\
\text { n-valeropherone-o-carboxylic acid }\end{array}$ \\
\hline Furanocoumarins & psoralen, bergapten, archangelicin \\
\hline Organic acids & ferulic acid, succinic acid, myristic acid \\
\hline Miscellaneous & $\begin{array}{l}\text { Vitamins A, B, E, polysaccharides including } \\
\text { AR-4E-2, angelica immunostaining }\end{array}$
\end{tabular}




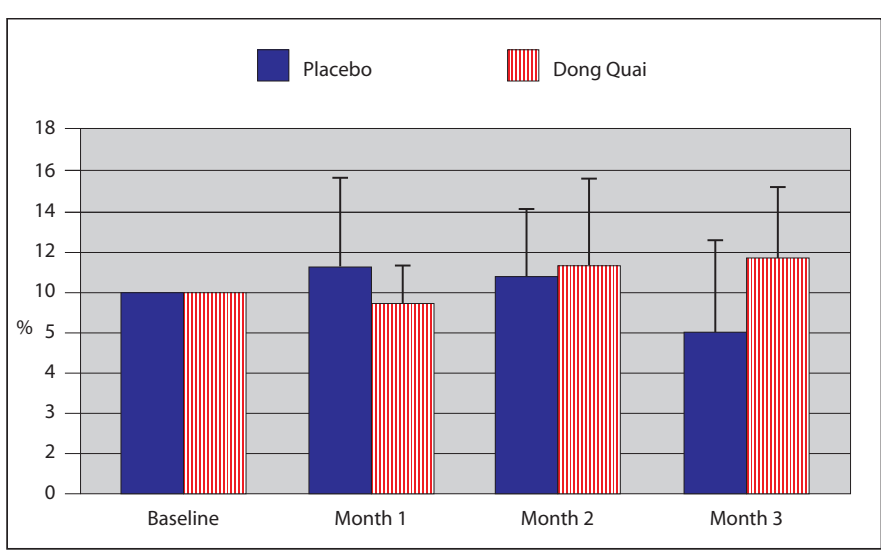

Fig. 3. Percent change in perceived hot flash severity. Vasomotor events were of similar severity in both groups $(p=0.79)$. There was no change in the severity of hot flashes experienced by either group ( $p=$ not significant).

and follow-up studies were normal in all patients. There were no clinical bleeding problems during the study interval.

The average baseline serum PSA for the placebo group was 0.21 , however this increased to 1.11 at the end of the study due to one patient's progression to androgen refractory disease while in the study. In the Dong Quai group the mean baseline PSA was 0.3 and 0.39 at the end of the study (Table 1).

\section{Discussion}

Despite patients' increasing interest and willingness to try alternative therapies, there is a lack of scientific evidence to support many of these over-the-counter treatments. Most of these treatments are not subject to the same regulatory scrutiny as pharmaceuticals, as they do not require review by Food and Drug authorities before they are marketed.

Dong Quai, or angelica sinensis, is a herbal therapy that has been used extensively for the treatment of gynecological disorders for thousands of years in traditional Chinese, Korean and Japanese medicine. The therapeutic dose is uncertain however, with studies in the gynecologic literature using varying dosages from $75 \mathrm{mg}$ to $1 \mathrm{~g} .^{2-4}$

The known constituents of Dong Quai are listed in Table $3 .^{10}$ It had been believed that many of its effects were related to a phytoestrogenic effect, however this assumption is now questioned. ${ }^{1,11}$ Animal studies have failed to identify any estrogenic activity. ${ }^{1,12}$

Adverse effects related to the use of Dong Quai appear to be very rare. Diarrhea and photosensitivity have been reported. ${ }^{11}$ As one component of Dong Quai includes furanocoumarins, the potential exists for potentiation of bleeding complications for those patients receiving concomitant anticoagulant therapy. ${ }^{11-13}$ We did not identify any bleeding complications in our series.
Hot flashes induced by ADT are typically described as a sudden onset of flushing sensation involving the face and neck. Huggins, Stevens and Hodges in their seminal work on the effects of castration for men with advanced prostate cancer described hot flashes as "profuse perspiration, often occurring at night, forcing the patient to throw off the bed covers" ${ }^{14}$ Prostate cancer patients receiving ADT commonly experience similar vasomotor symptoms as menopausal women. Although most men do not require treatment, a prospective trial found that $11.3 \%$ of patients found hot flashes distressing enough to negatively affect their quality of life. ${ }^{9}$

Various pharmaceuticals have been used for those men requiring therapy with varying degrees of success. Cyproterone acetate, medroxyprogesterone acetate and clonidine have been reported to be helpful in some patients, although not without the cost of inducing their own side effects. ${ }^{15,16}$ Estrogens have also been used, however the cardiovascular side effects have limited their application. ${ }^{17,18}$ The antidepressant venlafaxine also demonstrated efficacy in reducing hot flashes, but in a small non-placebo controlled series it was associated with a $10 \%$ dropout rate due to nausea. ${ }^{19}$ The most successful results have been reported with the progestational agent megestrol acetate. In a placebo-controlled crossover trial, hot flash frequency was diminished by $85 \% .{ }^{20}$ Two prior studies identified a $20-30 \%$ decrease in the frequency of hot flashes during a 4-week placebo run-in phase. ${ }^{20,21}$

Limitations of this study include the small pilot sample size which might miss a mild potential benefit, and the individual subjectiveness of recording hot flash severity. As the therapeutic dose of Dong Quai is unknown, it is possible that a different outcome may have been observed at a higher dosage or with a longer duration of treatment.

\section{Conclusion}

Hormonally treated prostate cancer patients taking Dong Quai in this pilot study showed no change in the duration or severity of their vasomotor events. Dong Quai was welltolerated and safe, but its benefits remain unproven for this population of patients.

From the Division of Urology, Schulich School of Medicine \& Dentistry, The University of Western Ontario, London, ON

Competing interests: None declared.

This paper has been peer-reviewed. 


\section{References}

1. Zhu D. Dong Quai. Am J Chin Med 1987;15:117-25.

2. Rotem C, Kaplan B. Phyto-female complex for the relief of hot flashes, night sweats and quality of sleep: Randomized, controlled, double-blind pilot study. Gynecol Endrocinol 2007;23:117-22.

3. Burke B, Olson R, Cusack B. Randomized controlled trial of phytoestrogen in the prophylactic treatment of menstrual migraine. Biomed Pharmacother 2002;56:283-8.

4. Hirata JD, Swiersz LM, Zell B, et al. Does dong quai have estrogenic effects in postmenopausal women? A double-blind, placebo-controlled trial. Fertil Steril 1997;68:981-6.

5. Nelson J. Hormone therapy for prostate cancer. In: Wein AJ, Kavoussi LR, Novick AC, Partin AW, Peters CA, editors. Campbell-Walsh Urology, 9th ed. Philadelphia; Sanders; 2007; 3090.

6. Yuzurihara $M$, lkarashi $Y$, Noguchi $M$, et al. Involvement of calcitonia gene-related peptide in elevation of skin temperature in castrated male rats. Urology 2003;62:947-51.

7. Parmer H, Edwards L, Phillips RH, et al. Orchiectomy versus long acting D-Trp-6-LHRH in advanced prostate cancer. Br J Urol 1987;59:248-54.

8. Smith JA Jr. Androgen suppression by a gonadotropin releasing hormone analogue in patients with metastatic carcinoma of the prostate. J Urol 1984;131:1110-2.

9. Spetz AC, Hammar M, Lindberg B, et al. Prospective evaluation of hot flashes during treatment with parenteral estrogen or complete androgen ablation for metastatic carcinoma of the prostate. J Urol 2001:517-20

10. Noe J. Angelica Sinensis: A monograph. J Naturopath Med 1997;7:66-72.

11. Boon, H, Smith M: Dong Quai. In: Health care professional training program in complementary medicine. Toronto: Wampole; 1997:96-9.
12. Page RL 2nd, Lawrence JD. Potentiation of warfarin by dong quai. Pharmacotherapy 1999;19:870-6.

13. Xvan GC, Feng QF, Xue FM. Clinical observation on treating 400 cases of cerebral infarction with traditional Chinese herb powder. Henan Journal of Traditional Chinese Medicine and Pharmacy 1997;12:28-9.

14. Huggins C, Stevens RE Jr, Hodges CV. Studies on prostatic cancer II. The effects of castration on advanced carcinoma of the prostate gland. Arch Surg 1941;43:209-23.

15. Eaton AC, McGuire N. Cyproterone acetate in treatment of postorchidectomy hot flashes. Double-blind cross-over trial. Lancet 1983;2:1336-7.

16. Charig CR, Rundle IS: Flushing: long term side effects of orchiectomy in treatment of prostatic carcinoma. Urology 1989;33:175-8.

17. Atala A, Amin M, Harty Jl. Diethylstilbesterol in treatment of post orchiectomy vasomotor symptoms and its relationship with serum follicle-stimulation hormone, luteinizing hormone and testosterone. Urology 1992;39:108-10.

18. Parra RO, Gregory JG. Treatment of post-orchiectomy hot flashes with transdermal administration of clonidine. J Urol 1990;143:753-4.

19. Quella SK, Loprinzi CL, Sloan J, et al. Pilot evaluation of venlafaxine for the treatment of hot flashes in men undergoing androgen ablation therapy for prostate cancer. J Urol 1999;162:98-102.

20. Loprinzi CL, Michalak JC, Quella SK, et al. Megestrol acetate for the prevention of hot flashes. N Engl J Med 1994;331:347-52.

21. Loprinzi CL, Goldberg RM, $0^{\prime} F$ allon JR, et al. Transdermal clonidine for ameliorating post-orchiectomy hot flashes. J Urol 1994;151:634-6.

Correspondence: Dr. Hassan Razvi, Urology, St. Joseph's Hospital, 268 Grosvenor St., London, ON N6A 4V2; fax: 519-646-6037; hrazvi@uwo.ca 